\title{
Effect of Intercritical Heat Treatment on Mechanical Properties of Reinforcing Steel Bars
}

\author{
MUHAMMAD ISHAQUE ABRO*, RIAZ AHMED MEMON*, IMTIAZ ALI SOOMRO*, AND UMAIR AFTAB* \\ RECEIVED ON 15.02.2016 ACCEPTED ON 22.11.2016
}

\begin{abstract}
Intercritical heat treatments attempts were made to enhance the mechanical properties of reinforcing steel bars milled from scrap metal. For this, two grades of steel bars were obtained from different steel mills and their mechanical properties that include hardness, ultimate tensile strength, and percent elongation before and after intercritical heat treatment were determined. Results indicated that 25.5 and 17.6\%, improvements in UTS (Ultimate Tensile Strength) and 18.8 and 14.3\% improvement in percent elongation in two grades of reinforcing steel samples containing 0.17 and $0.24 \%$ carbon respectively was achieved while heating at $750^{\circ} \mathrm{C}$ for $2 \mathrm{~h}$. Appreciable improvement in the mechanical properties was noted due to birth of sufficient quantity of martensite along with ferrite.
\end{abstract}

Key Words: Reinforcing Steel, Intercritical Heat Treatment, Mechanical Properties.

\section{INTRODUCTION}

$\mathrm{T}$ he most common steels used in the automobile and structural applications are low-carbon steels having low strength level and good formability. Despite their forming and cost advantages over high strength steels, the ultimate strength level of these steels remains at relatively low levels which is compensated with increasing the cross-sectional area of the material. Traditional strengthening methods are alloying and work hardening which are not cost effective[1]. Production of steels with improved mechanical properties at lowest possible cost is therefore a matter of practical significance [2]. To achieve this goal dual phase steels were developed [2-3].

Dual-phase steels, developed in 1970s, are an important member of AHSS (Advanced High Strenth Steels). These steels have a composite microstructure consisting of hard martensite particles/islands embedded in a continuous soft ferrite matrix. Dual phase steel with ferrite-martensite microstructures possess a number of important mechanical properties like high initial strain hardening rate, high strength, good ductility and toughness which distinguish them from conventional steel. Besides these features, dual phase steels shows continuous yielding behavior, low yield to tensile strength ratio (YS/TS), high formability and good fatigue resistance[4,5]. These properties are due to the combined effect of two phases present in dual phase steel in which martensite controls the strength of the steel while ferrite is responsible for formability properties [5,9].

Reinforcing steel bar is very important construction material in this modern world, the skyscrapers such as

* Department of Metallurgy \& Materials Engineering, Mehran University of Engineering \& Technology, Jamshoro.

Mehran University Research Journal of Engineering \& Technology, Volume 36, No. 3, July, 2017 [p-ISSN: 0254-7821, e-ISSN: 2413-7219] 
BurjKhailifa, Petronas Towers have become only possible because of these reinforcing bars. In most of the civil structures reinforcing steel bars made of plain carbon steel are used worldwide, while in construction of military structures, and bridges alloy steel is also used to manufacture reinforcing bars. In developing countries the steel used for reinforcing bars are manufactured from scrap material due to which their chemico-mechanical properties are not equivalent to international standards. In Pakistan mostly the private mills producing reinforcing steel bars use the scrap that come from ship braking industry and obsolete automobiles, whereas government mills are using billet whose bars are expensive. In result the utilization of bars manufactured from scrap is quite higher despite their poor chemico-mechanical properties.In present study attempt has been made to improve the properties of reinforced steel bars through intercritical heat treatment process which is not in practice worldwide particularly in Pakistan. It is worth mentioning that traditionally the reinforced bars are heat treated by conventional methods by which ferrite-pearlite microstructure produces, thus improvement in mechanical properties is very marginal. In contrast, by implementing the intercritical heat treatment the substantial improvement in the properties of steels grades milled from scrap metal has been achieved.

\section{EXPERIMENTAL WORK}

\subsection{Material Collection}

The reinforcing steel bars studied in present work were manufactured by Magna Steel Mills and Amreli Steel Mills Pakistan. These Mills are manufacturing the reinforce steel bars from steel scrap.

\subsection{Chemical Composition}

The chemical composition of as received bars given in Table 1 was determined using optical spark emission spectrometer (Bruker-Q2 ion).

\subsection{Sample Preparation}

From each grade of reinforced steel bars six tensile test samples of the geometry shown in Fig. 1 were prepared. During cutting water was used to avoid the localized heating effect. Thereafter samples were polished using 500 mesh emery paper to minimize the surface stress raisers. From each grade of reinforcing bars samples were selected for heat treatment and for tensile testing.

TABLE 1. CHEMICAL COMPOSITION OF STEEL BARS

\begin{tabular}{|c|c|c|c|c|c|c|}
\hline \multirow{2}{*}{ Grade } & \multicolumn{5}{|c|}{ Composition } \\
\cline { 2 - 7 } & C (\%) & Si (\%) & Mn (\%) & P (\%) & S (\%) & Fe (\%) \\
\hline Grade-1 & 0.17 & 0.18 & 0.97 & 0.02 & 0.02 & 98.64 \\
\hline Grade-2 & 0.24 & 0.24 & 0.66 & 0.03 & 0.01 & 98.82 \\
\hline
\end{tabular}

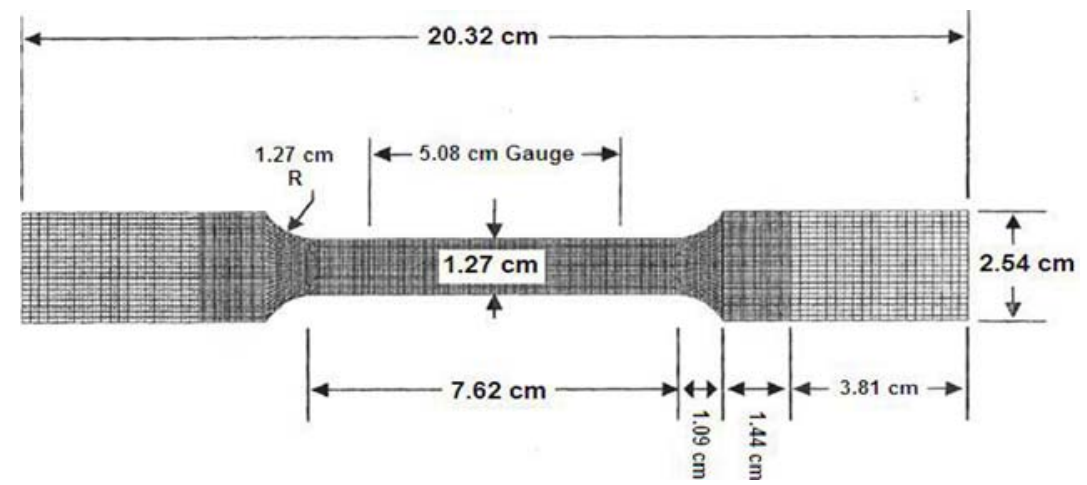

FIG. 1. TENSILE SPECIMEN

Mehran University Research Journal of Engineering \& Technology, Volume 36, No. 3, July, 2017 [p-ISSN: 0254-7821, e-ISSN: 2413-7219] 


\section{$2.4 \quad$ Heat Treatment}

The tensile test samples prepared from reinforcing steel bars were subjected to five different heat treatment conditions. Description of heat treatment conditions along with samples code (ID) is given in Table 2 and schematically represented in Fig. 2. Fig. 2 indicates that among the five heat treatment conditions were performed and out of them four conditions belongs to inter critical heat treatment, whereas the fifth belongs to conventional heat treatment operation. In each heat treatment samples were heated in Muffle furnace (Fig. 2) set at prescribed temperature for specific time interval and then quenched in water.

\subsection{Mechanical Testing}

Tensile tests of as received and heat treated samples were performed using Zwick/Roell (Model: A65272) UTM

TABLE 2. HEAT TREATMENT CONDITIONS PERFORMED ON REINFORCED SAMPLES

\begin{tabular}{|c|c|c|c|c|c|c|}
\hline Heat Treatment ID & A & B & C & D & E & F \\
\hline Heating Temperature $\left({ }^{\circ} \mathrm{C}\right)$ & - & 750 & 750 & 850 & 850 & 950 \\
\hline Soaking Time (hour) & - & 1 & 2 & 1 & 2 & $1 / 3$ \\
\hline
\end{tabular}

(Universal Tensile Testing Machine). Tensile testing speed was set $3 \mathrm{~cm} / \mathrm{min}$. Vicker hardness testing machine was used to measure hardness of the samples at $10 \mathrm{~kg}$ load.

\subsection{Metallography}

The microstructures of as received and heat treated samples were examined using optical microscope. Metallographic specimens were prepared using conventional grinding and polishing techniques. In grinding stage emery paper of 200, 350, 500, 700, 1000, and 1200 mesh size were used, whereas final polishing was carried out using diamond paste. Finally samples were etched in 2\% Nital prepared by adding $2 \%$ concentrated nitric acid in methanol solution.

\section{RESULTS AND DISCUSSION}

\subsection{Hardness}

Vicker hardness result of Grade-1 and Grade-2 of as received and heat treated reinforcing steel bar specimens aregraphically represented in Fig. 3(a-b). Hardness profile, shown in Fig. 3(a-b) indicates that hardness increasing and decreasing trend of Grade-1 and Grade-2 steel bar specimens at different heat treatment conditions is similar.

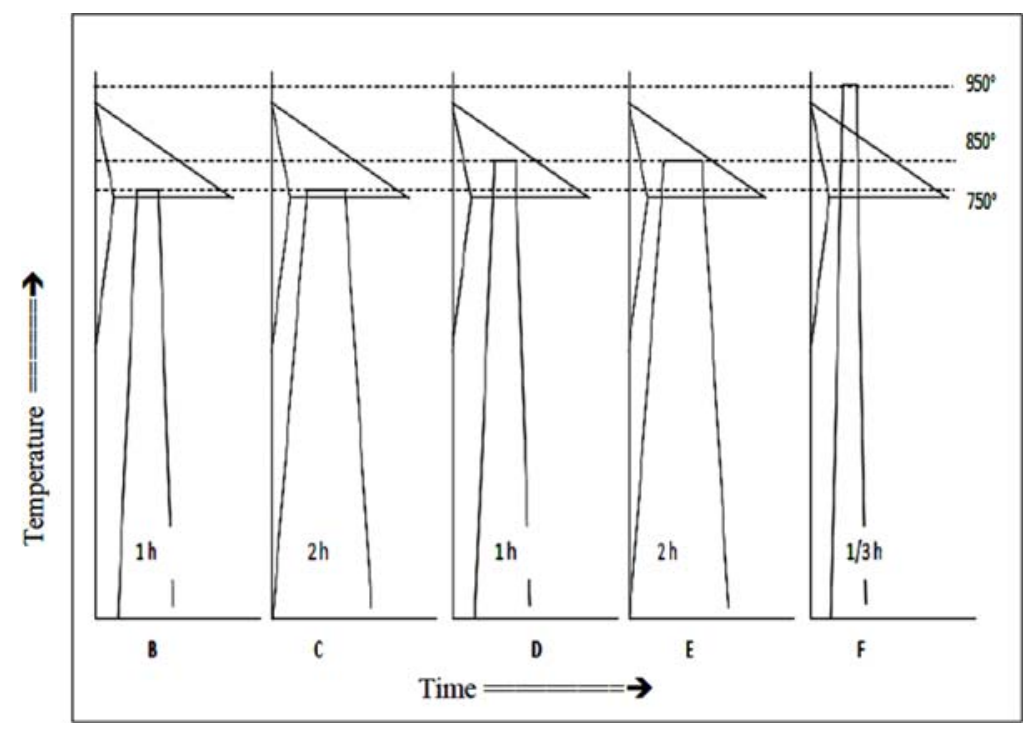

FIG. 2. HEAT TREATMENT CONDITIONS PERFORMED ON REINFORCED STEEL BARS 
The difference in hardness among reinforcing steel bar specimens of Grade- 1 and Grade- 2 can be explained in terms of microstructural constituents and carbon content. In as received conditions Grade- 1 bar specimens contain low volume fraction of pearlite in comparison with Grade2 bar specimens.

The hardness results of Grade- 1 and Grade- 2 confirm the significance of volume fraction of microphases on mechanical properties. Sufficiently higher hardness value of Grade-2 specimens as compared to grade 1is plainly due to higher carbon content, higher martensite volume fraction and finer grain size.
The etiology of the appreciable increase in the hardness of grade 1 samples containing $0.17 \%$ C and Grade- 2 samples containing $0.25 \% \mathrm{C}$ with implementation of inter critical heat treatment as compared to conventional heat treatment was elucidated by the examination of microstructures developed in each grade at different heat treatment conditions. The microstructural investigations revealed that both samples (Grade-1 and Grade-2) in normalized conditions were composed of pro-eutectoid ferrite and pearlite with the minor variation in the volume fraction of pearlite. When the samples were subjected to B, C, D, and E inter critical heat treatments it was possible
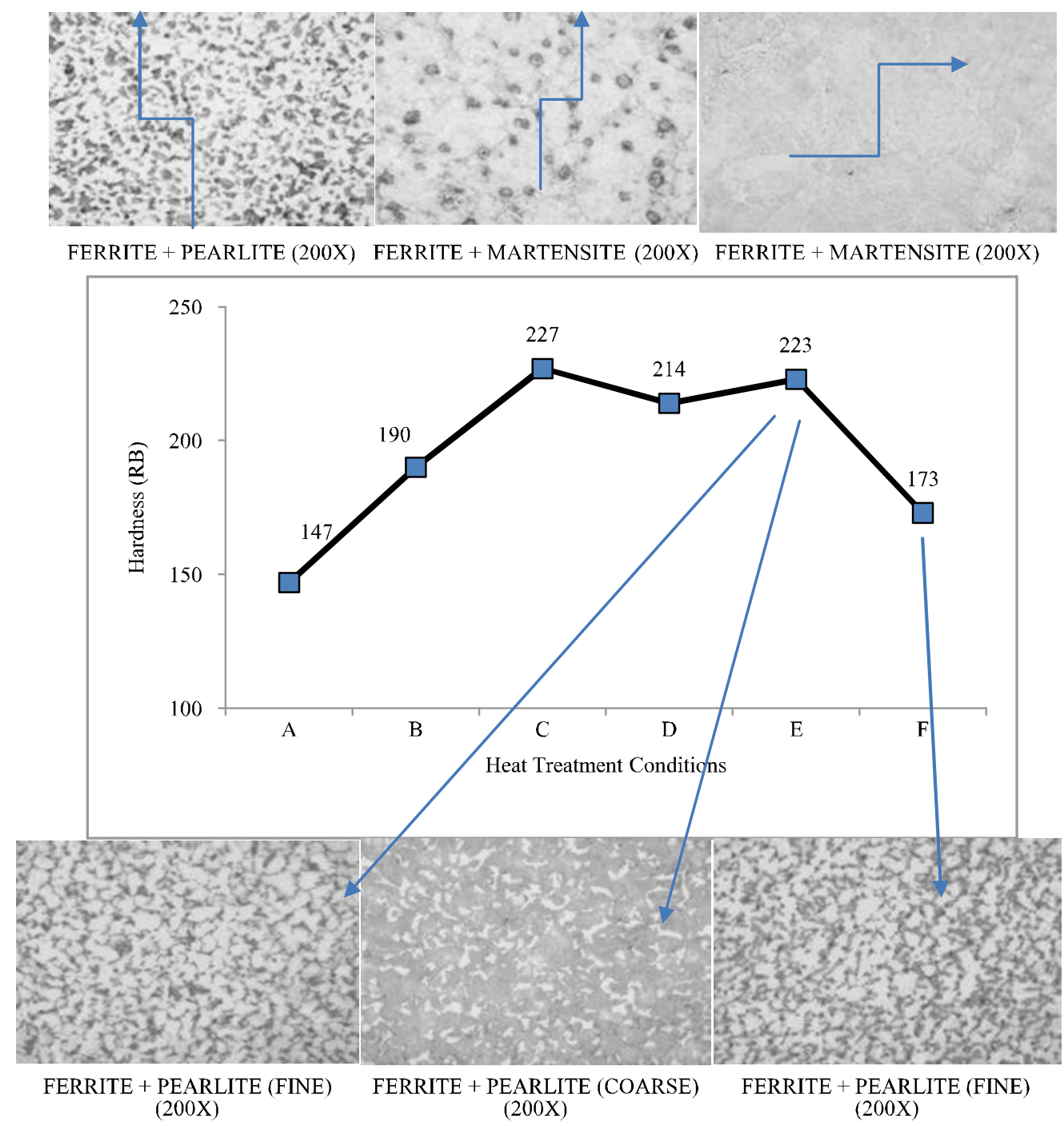

FIG. 3(a). EFFECT OF HEAT TREATMENT ON HARDNESS AND MICROSTRUCTURE ON GRADE 1 STEEL BAR SAMPLES

Mehran University Research Journal of Engineering \& Technology, Volume 36, No. 3, July, 2017 [p-ISSN: 0254-7821, e-ISSN: 2413-7219] 
to produce martensite which was otherwise not possible by conventional heat treatment. The modifications achieved in the microstructures of Grade- 1 and Grade- 2 samples through inter critical and conventional treatments are also shown in Fig. 3(a-b) respectively. It can be seen from micrographs given in Fig. 3(a-b) that in Grade-1 and Grade-2 samples martensite network surrounded by ferrite grains was developed by implementing "B" inter critical heat treatment. In case of " $\mathrm{C}$ " heat treatment condition where only the soaking time was increased to $2 \mathrm{~h}$ while maintaining heating temperature at $750^{\circ} \mathrm{C}$, it was noted that volume fraction of martensite network was increased as compared to " $\mathrm{B}$ " heat treatment. For intercritical heat treatment condition " $\mathrm{D}$ ", "E" and " $\mathrm{F}$ " microstructural study did not revealed the development of ferritemartensite rather it was noted that ferrite-pearlite with minor variation in the volume fraction was formed. This alteration in microstructures of the Grade- 1 and Grade- 2 samples clearly support the cause of variation in hardness achieved through different heat treatments.

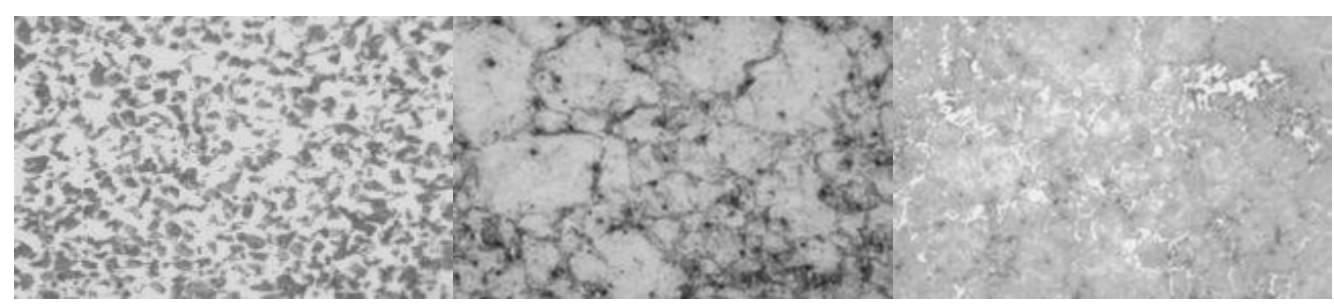

FERRITE + PEARLITE (200X) FERRITE + MARTENSITE (200X) FERRITE + MARTENSITE (200X)
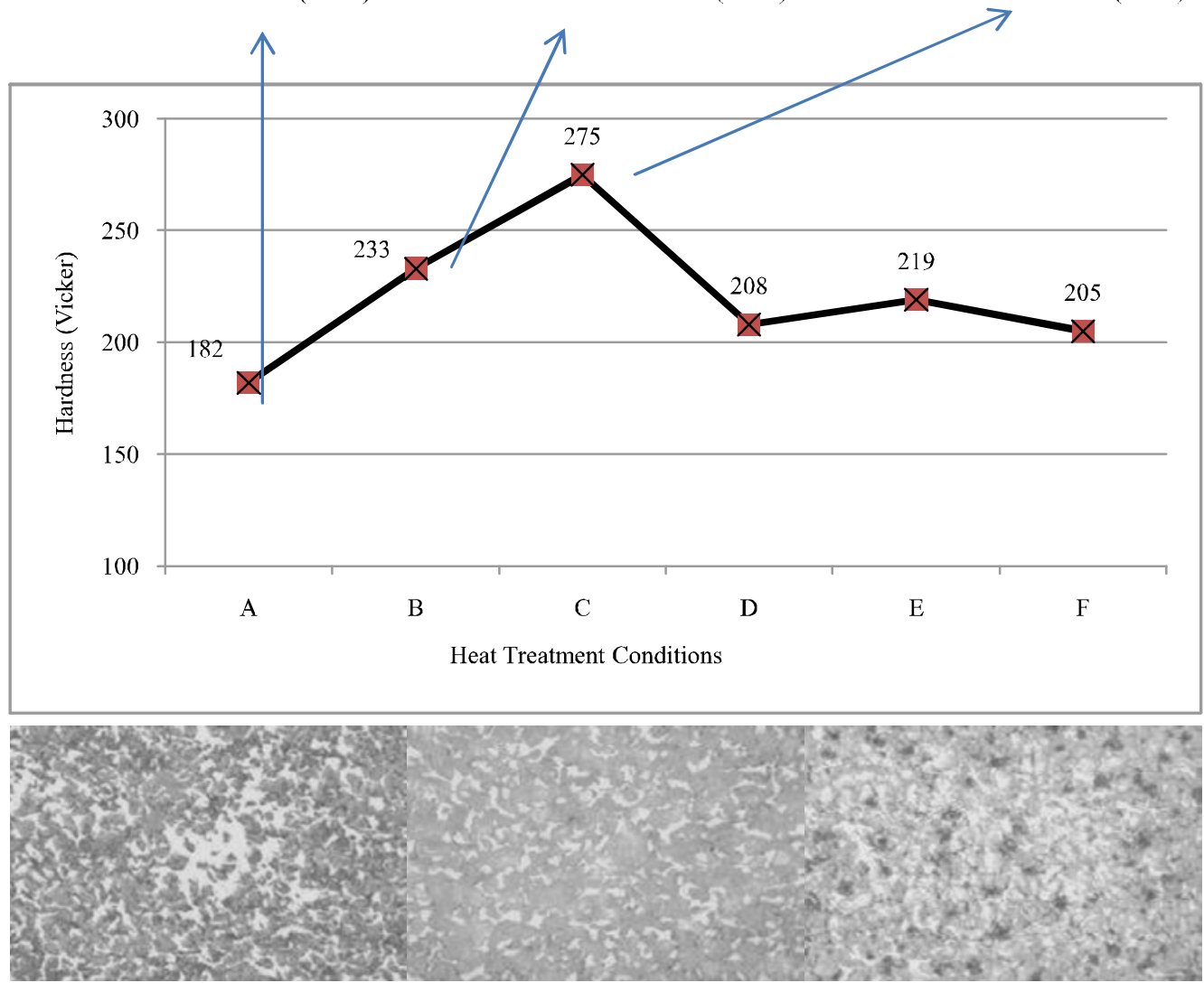

FERRITE + PEARLITE (200X)

FERRITE + PEARLITE (200X)

FERRITE + PEARLITE (200X)

FIG. 3(b). EFFECT OF HEAT TREATMENT ON HARDNESS AND MICROSTRUCTURE ON GRADE 2 STEEL BAR SAMPLES

Mehran University Research Journal of Engineering \& Technology, Volume 36, No. 3, July, 2017 [p-ISSN: 0254-7821, e-ISSN: 2413-7219] 


\subsection{Tensile Properties}

Tensile test result of as received and heat treated reinforcing steel bar specimens are graphically shown in Fig. 4(a-b) which represents the UTS and percent elongation verses heat treatment conditions respectively.

It can be understood from the graphs that tensile strength, yield strength and percent elongation of all dualphase steels is higher than those of as-received specimens.

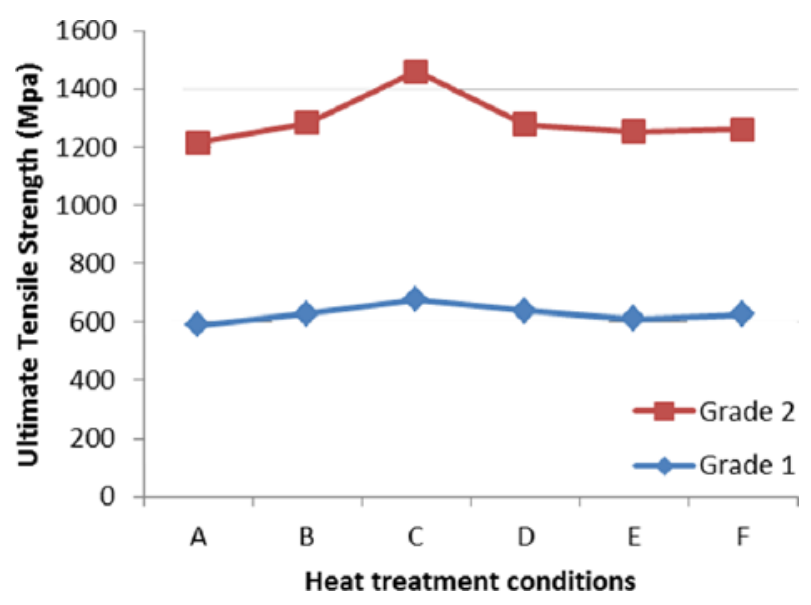

FIG. 4(a). ULTIMATE TENSILE STRENGTH OF GRADE-1 AND GRADE-2 STEEL BAR SPECIMENS AT DIFFERENT HEAT TREATMENT CONDITIONS

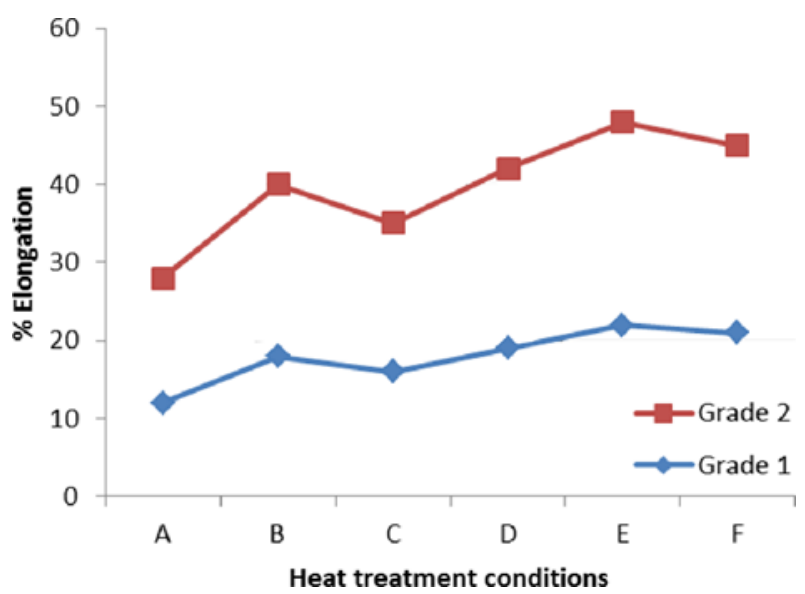

FIG. 4(b). \% ELONGATION OF GRADE-1 AND GRADE-2 STEEL BAR SPECIMENS AT DIFFERENT HEAT TREATMENT CONDITIONS
When dual phase induced specimens of both gradesare compared with each other, it is observed that the maximum tensile strength and yield strength, have been attained for the specimens subjected to heat treatment condition $\mathrm{C}$ (heated at $750^{\circ} \mathrm{C}$ for 2 hours). This can be attributed due to maximum martensite volume fraction obtained when specimens are subjected to heat treatment condition C.

Moreover Fig. 4(b) indicates that maximum increase in percent elongation is obtained when specimens were subjected to heat treatment condition " $E$ " (heated at $850^{\circ} \mathrm{C}$ for 2 hours). This can be attributed with presence higher volume fraction of ferrite and coarser grain size of pearlite and ferrite. Contrary specimens subjected to heat treatment condition $\mathrm{C}$ as compared to other heat treated specimens indicated the minimum percent elongation value. This can be described by considering the higher volume fraction of martensite network produced in these specimens compared to others.

\subsection{Comparison of Results}

Comparing the UTS and percent elongation values of reinforcing steel bar specimens of Grade-2 are comparatively better than Grade-1.

To validate the significance of inter-critical heat treatment the improvements in the UTS and percent elongation of locally manufactured reinforced bars were compared with the improvements reported for reinforced bars . Oguzhanet. al. [2] and Alanemeet. al. [11] have attempted the inter-critical heat treatment to improve the properties of reinforced bars of Eregli Iron and Steel Turkey and Ispat Steel Nigeria. The results shown in Figs. 5-6 validate that substantial improvement achieved in the UTS and percent elongation respectively by employing the intercritical heat treatment on locally manufactured reinforced bars are in consistent with other international reinforced bars of SAE 1010 steel grade. The general trend of the variation in the UTS and percent elongation results shown in Figs. 5-6 clearly demonstrate that in case of inter-critical heat treatment condition soaking time is a critical factor that played a significant role in the modification of the properties.

Mehran University Research Journal of Engineering \& Technology, Volume 36, No. 3, July, 2017 [p-ISSN: 0254-7821, e-ISSN: 2413-7219] 


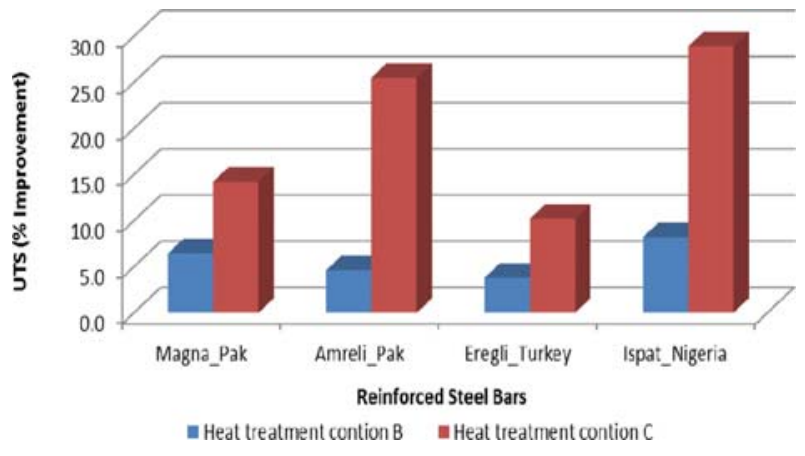

FIG. 5. EFFECT OF INTER-CRITICAL HEAT TREATMENT ON UTS OF PAKISTAN, TURKEY AND NIGERIA REINFORCED STEEL BARS

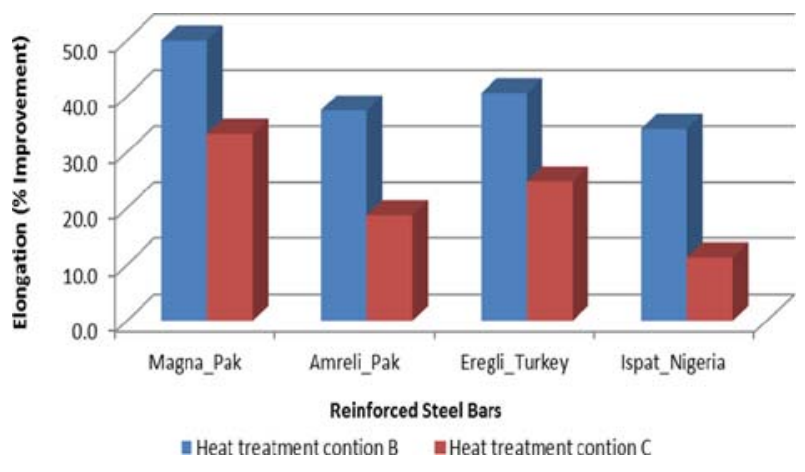

FIG. 6. EFFECT OF INTER-CRITICAL HEAT TREATMENT ON ELONGATION OF PAKISTAN, TURKEY AND NIGERIA REINFORCED STEEL BARS

\section{CONCLUSIONS}

(i) The results indicate that the strength of the specimens having ferrite-martensite dual phase microstructure has been significantly improved which were intercritical heat treated as compared to as conventionally heat treated specimen.

(ii) It has been found from the result that in case of inter-critical heat treatment soaking time is a critical factor that played a significant role in the modification the microstructure and mechanical properties of dual phase steel specimens. The volume fraction of martensite has increased and the average grain size decreased with increasing the soaking time. The strength of the DP steel specimens is function of hardness and volume fraction of the martensite phase. (iii) The highest values of hardness, tensile and yield strength of the specimens having dual phase microstructure have been found when specimens were heated at $750^{\circ} \mathrm{C}$ for two hours. While maximum percent elongation has been achieved when specimens were heated at $850^{\circ} \mathrm{C}$ for two hours.

\section{ACKNOWLEDGEMENTS}

The authors would like to thank the Magna Steel Mill and Amreli Steel Mill, Karachi, Pakistan, for providing the rebars required for the present work. Authors would also thank to the Chairperson, Department of Metallurgy \& Materials Engineering Mehran University of Engineering \& Technology, Jamshoro, Pakistan, for providing experimental facilities.

\section{REFERENCES}

[1] Aksoy, M., and Esin, A., "Improving the Mechanical Properties of Structural Carbon Steel by Dual-Phase Heat Treatment”, Journal of Materials Engineering, Volume 10, No. 4, pp. 281, 1988.

[2] Oguzhan, K., HalidunK.M., and Yildiz, S., "Improvement of Mechanical Properties of Reinforcing Steel Used in the Reinforced Concrete Structures", Journal of Iron and Steel Research, International, Volume 16, No. 3, pp. 55-63, 2009.

[3] Aksoy, M., "An Investigation on the Improvement of Mechanical Properties of Reinforcing Steel by DualPhase Treatment [D]”, Elazig, Firat University Institute of Science and Technology, (Turkish), 1985.

[4] Zidelmel, S., Sahraoui, T., and Mohhamed, H., "Microstructure and CharpyImpact Properties of Ferrite-MartensiteDual Phase X70 API-Line Steel”, Materials Science and Engineering-A, Volume 598, pp. 338-342, 2014.

[5] Movahed, P., Kolahgar, S., Marashi, S.P.H., Pouranvari, M., and Parvin, N., "The Effect of Intercritical Temperature on the Tensile Properties and Work Hardening Behavior of Ferrite-Martensite Dual Phase Steel”, Materials Science and Engineering-A, Volume 518, pp. 1-6, 2009. 
[6] Prohaszka, J., and Dobranszky, J., “Quality Improvement of Low Carbon Reinforcing Steel by Rapid Heat Treatment”, Journal of Heat Treating, Volume 9, No. 1, pp. 63-6, 1991.

Sarkar, P.P., Kumar, P., and Chakraborti, P.C., "Microstructure-Based Evaluation of Stress Corrosion Cracking Behaviour of Dual-Phase Steels in 3.5\% $\mathrm{NaCl}$ Solution”, Journal of Materials Science and Applications, 2013

[8]

Davies, R.G., "Influence of MartensiteComposition and Content on the Properties of Dual-Phase Steels”, Metall Transaction-A, Volume 9, pp. 671-676, 1978.

Fereiduni, E., and Ghasemi Banadkouki, S.S., "Improvement of Mechanical Properties in a Dual-Phase Ferrite-Martensite AISI4140 Steel under Tough-Strong Ferrite Formation”, Materials and Design. Volume 56, pp. 232-240, 2014.

[10] Alaneme, K.K., Adejumo, O.J., and Borode, J.O., “Influence of Different Cyclic Inter-Critical Heat Treatment Schedules on the Microstructure and Mechanical Behaviour of a Dual Phase Medium Carbon Low Alloy Steel”, Metallurgy \& Materials Engineering, Volume 19, No. 2, pp. 155-165, 2013.
[11] Kumar, A., Singh, S.B., and Ray, K.K., "Influence of Bainite/Martensite-Content on the Tensile Properties of Low Carbon Dual-Phase Steels”, Journal of Materials Science \& Engineering-A, Volume 474, pp. 270-282, 2008.

[12] Saeidi, N., and Ekrami, A., “Comparison of Mechanical Properties of Martensite/Ferrite and Bainite/Ferrite Dual Phase 4340 Steels”, Journal of Materials Science \& Engineering-A, Volume 523, pp. 125-129, 2009.

[13] Erdogan, M., "The Effect of New Ferrite Content on the Tensile Fracture Behaviour of Dual Phase Steels”, Journal of Materials Science, Volume 37, pp. 3623-3630, 2002.

[14] Yi, J.J., Kim, I.S., and Choi, H.S., “Austenitization during Intercritical Annealing of an Fe-C-Si-Mn Dual-Phase Steel”, Journal of Metallurgical Transactions-A, Volume 16A, pp. 1237-1245, 1985.

[15] Salvatore, W., Buratti, G., Maffei, B., and Valentini, R., "Dual Phase Steel Rebarsfor High Ductile RC Elements, Part-2: Rotational Capacity of Beams”, Journal of Engineering Structures, Volume 29, No. 12, pp. 3333-3341, 2007. 